\title{
Presbyopia in Yenagoa, Bayelsa State, Nigeria
}

\section{R Azonobi}

Department of Ophthalmology, Niger Delta University, Okolobiri, Yenagoa, Bayelsa State, Nigeria

\section{ABSTRACT}

Objective: To determine the pattern of presentation of presbyopia in Yenagoa.

Method: All consecutive new patients presenting to the eye clinic of the Department of Ophthalmology of the Niger Delta University complaining of blurred vision or asthenopia while doing near work, whose near acuity improved to at least N8 (Jaeger) with the addition of a convex lens were studied. Distance and near acuity were done using the Snellen and the Jaeger charts respectively, followed by a full ocular examination including objective and subjective refraction. Statistical analysis was done using the statistical package for social scientists (SPSS, 11.0).

Results: A total of 1168 new patients were reviewed, out of which 149 were diagnosed as presbyopic. There were 73 males and 76 females (M: $\mathrm{F}=1: 1.04)$, with an age range of $34-83$ years (mean 45.6 years: $S D \pm 4.172$ ). Most of the patients $(72.5 \%)$ were emmetropes. Hypermetropia was the commonest refractive error $(16.8 \%)$ followed by astigmatism (8.7\%). Myopia was found to be rare (2.0\%).

The earliest age at presentation was 34 years with a mean of 45.6 years $(\mathrm{SD} \pm 4.172)$ for both sexes. The mean add requirement for the male patients was +2.061 $(\mathrm{SD} \pm 0.470)$ while that for the female patients was +1.715 $(\mathrm{SD} \pm 0.345)$. The difference in add requirement was found to be statistically significant $(\mathrm{p}=0.00001)$.

Conclusion: Presbyopia occurred early among the population studied. The add requirement was also high. The mean add requirement for male patients was found to be higher than that for the female patients.

Keywords: presbyopia, add, onset, Yenagoa, hypermetropia, near vision

\section{INTRODUCTION}

Presbyopia is the most common physiological change occurring in the adult eye, leading to near vision impairment with advancing age. ${ }^{1}$ Among Caucasians, presbyopia usually sets in between the age of 40 to 45 years. $^{2}$ However, clinic based studies in Africa have reported an earlier age of onset. $^{3,4}$
The onset of presbyopia is said to be influenced by environmental temperature, with onset earlier in hotter climates, ${ }^{5,6}$ although this was not supported by a study in Nigeria. ${ }^{7}$ The onset of presbyopia has been found to occur earlier in women compared to men. ${ }^{8,9}$

Presbyopic refraction was thought to vary linearly in consonance with age-related decline in the amplitude of accommodation. However, current available evidence does not support this observation. Presbyopic refraction is now believed to increase linearly with age up to the early fifties. In the mid-fifties however, there is a decline, and this is believed to be due to changes in the lens. ${ }^{10}$ Presbyopic refraction is said to be gender and environment dependent and therefore varies from one geographic location to another. Hofstetter and Kragha, in comparing presbyopic refraction between Canadian and Puerto Rican subjects, established that presbyopic refraction in Canadians is less than in Puerto Ricans. ${ }^{11}$ Females also have a higher presbyopic refraction than their age-matched males. ${ }^{8}$

The prevalence of presbyopia is highly variable throughout the world. This is due partly to the lack of agreement on its definition and its measurement and partly to the interplay of multiple factors including the environment, UV-radiation, chronic deficiency of essential amino acids and exposure to toxic factors. ${ }^{1,6}$ Previous studies show a prevalence of $85.4 \%$ in Kenya and $62 \%$ in Tanzania. ${ }^{12,13}$ In Eastern Nigeria, a prevalence of $33.3 \%$ and $27.5 \%$ were found in two separate studies. ${ }^{14,15}$

Presbyopia affects quality of life and productivity and can also limit potential educational achievement. ${ }^{16,17}$

To the best of our knowledge there is no previous publication on presbyopia in Bayelsa State, Nigeria. Niger Delta University Teaching Hospital eye clinic is the only functional ophthalmic unit in the state. As a result, cases seen here may be a reflection of the situation in the general population. In the absence of a population-wide survey on presbyopia, the findings of this study can be useful for the purposes of planning eye care services in the state.

\section{MATERIALS AND METHODS}

This study took place in the eye clinic of Niger Delta University Teaching Hospital, Okolobiri, Yenagoa, Bayelsa State, Nigeria, between March 2008 and February 2009. 


\section{Inclusion Criteria}

All consecutive new patients presenting with symptoms of presbyopia, whose near acuity improved to at least N8 with the addition of an appropriate convex lens were included.

\section{Exclusion criteria}

Patients with other ocular pathology whose near vision could not be improved to at least N8 with appropriate presbyopic correction were excluded.

\section{Method}

Distance and near acuity were determined using the Snellen and the Jaeger acuity charts. This was followed by a full ocular examination. An objective refraction was carried out using a Carl Zeiss $599^{\mathrm{R}}$ autorefractometer followed by a subjective refraction.

\section{Statistical Analysis}

All data were analysed using a statistical package (SPSS, 11.0).

\section{Results}

A total of 1168 new patients were seen during the study period, out of which $149(12.8 \%)$ were found to be presbyopic. Seventy-three (49\%) of these were male and 76 were female $(51 \%)$, giving a male:female ratio of approximately 1:1 (table 1 ). The age range was $34-83$ years with a mean of 45.6 years $(S D \pm 4.172)$. The mean age of the female patients at presentation was 43.94 years $(\mathrm{SD} \pm 4.105)$ and for males was 47.22 years ( $\mathrm{SD} \pm 4.243)$. The majority of the patients $(73.2 \%)$ were civil servants (table 2 ).

Table 1. Age and sex distribution of presbyopic patients

\begin{tabular}{lrcr}
\hline \multirow{2}{*}{$\begin{array}{l}\text { Age } \\
\text { years })\end{array}$} & \multicolumn{2}{c}{ Sex $\mathrm{n}(\%)$} & $\begin{array}{l}\text { Total } \\
\mathrm{n}(\%)\end{array}$ \\
\cline { 2 - 3 } $30-40$ & $22(14.8)$ & $27(18.1)$ & $49(32.9)$ \\
$41-50$ & $32(21.5)$ & $36(24.2)$ & $68(45.6)$ \\
$51-60$ & $9(6.0)$ & $13(8.7)$ & $22(14.8)$ \\
$61-70$ & $7(4.7)$ & 0 & $7(4.7)$ \\
$>70$ & $3(2.0)$ & 0 & $3(2.0)$ \\
\hline Total & $73(49.0)$ & $76(51.0)$ & $149(100.0)$ \\
\hline
\end{tabular}

Table 2. Occupation of respondents

\begin{tabular}{lcc}
\hline Occupation & No. & Percent \\
\hline Civil servants & 109 & 73.2 \\
Self-employed & 24 & 16.1 \\
Farmers & 5 & 3.4 \\
Unemployed & 4 & 2.7 \\
Pensioners & 4 & 2.7 \\
Students & 2 & 1.3 \\
Clergy & 1 & 0.7 \\
\hline Total & 149 & 100.0 \\
\hline
\end{tabular}

Table 3 shows the refractive status of the subjects. The majority of the patients $(72.5 \%)$ were emmetropes. Hypermetropia was the commonest error seen (16.8\%), followed by astigmatism ( $8.7 \%)$. Myopia was rare among the patients.

The presbyopic correction in the various age groups is shown in table 4 . The mean presbyopic correction for the male patients was $2.06(\mathrm{SD} \pm 0.47)$, while that for the female patients was $1.72(\mathrm{SD} \pm 0.35)$ with a mean of $2.05(\mathrm{SD} \pm 0.41)$ for both sexes. The difference in presbyopic correction for both sexes was statistically significant $(\mathrm{p}=0.00001)$.

Table 3. Refractive status of the presbyopic patients

\begin{tabular}{lcc}
\hline Refractive status & No. & Percent \\
\hline Emmetropia & 108 & 72.5 \\
Hypermetropia & 25 & 16.8 \\
Astigmatism & 13 & 8.7 \\
Myopia & 3 & 2.7 \\
\hline Total & 149 & 100.0 \\
\hline
\end{tabular}

Table 4. Presbyopic correction in the study population

\begin{tabular}{lccccc}
\hline $\begin{array}{l}\text { Age } \\
\text { (years) }\end{array}$ & \multicolumn{2}{c}{ Mean } & \multicolumn{1}{c}{\begin{tabular}{c} 
Mean \\
Add \\
\cline { 2 - 5 } M \& F
\end{tabular}} & Z Score & P value \\
\hline $30-34$ & 1.125 & 1.050 & 1.088 & 1.1066 & 0.2714 \\
$35-39$ & 1.325 & 1.340 & 1.333 & 0.2213 & 0.8414 \\
$40-44$ & 1.440 & 1.580 & 1.510 & 2.0658 & 0.0394 \\
$45-49$ & 1.800 & 1.676 & 1.738 & 1.8297 & 0.2802 \\
$50-54$ & 2.222 & 2.094 & 2.158 & 1.8887 & 0.2758 \\
$55-59$ & 2.333 & 2.250 & 2.292 & 1.2247 & 0.2224 \\
$60-64$ & 2.500 & - & 2.500 & - & - \\
$65-69$ & 2.800 & - & 2.800 & - & - \\
\hline 70 & 3.000 & - & 3.000 & - & - \\
\hline Total & 2.061 & 1.715 & 2.047 & 3.9021 & 0.00001 \\
\hline
\end{tabular}

\section{DISCUSSION}

The earliest age at presentation for presbyopia in this study was between the ages of 30-34 years. In Caucasians, presbyopia usually presents between the ages of 40-45 years ${ }^{212}$ and 37-39 years in Indians. ${ }^{18}$ Presbyopia also tends to present earlier in the tropics than in the temperate regions. ${ }^{5,19}$ Yenagoa in Nigeria has fairly high average temperatures all year round. This may explain the findings in this study. The mean age at presentation for females in this study was 43.94 years $(\mathrm{SD} \pm 4.11)$ and for males was 47.22 years $(\mathrm{SD} \pm 4.24)$. This is similar to the findings by Pointer ${ }^{8}$ and Ezepue. ${ }^{20}$ 
Hypermetropia was the commonest refractive error and myopia the least among the presbyopic patients in this study. This is consistent with the findings of Spierer and Shalev ${ }^{21}$ among male pilots in Israel. Hypermetropes use part of their amplitude of accommodation to correct part or all of their distance error depending on its magnitude, leaving them with less amplitude of accommodation than their age matched emmetropes or myopes. They therefore complain of symptoms of presbyopia much earlier than their age matched emmetropes or myopes ${ }^{21}$. This may explain why hypermetropia was the commonest error seen in the study population.

Presbyopic correction in this study was higher than that of age-matched Caucasians ${ }^{18}$ and Koreans ${ }^{20}$ prior to the age of 55 years. However, from the age of 55, the presbyopic correction in this study became less than for their agematched Caucasians and Koreans. Coates ${ }^{23}$ in his study, found that the amplitude of accommodation among Africans is less than that of their European counterparts. This may explain why this study found a greater presbyopic correction than was used for age-matched Caucasian prior to the age of 55 . The reduced presbyopic correction from age 55 may be due to the effect of lenticular sclerosis, which is common in this age group. ${ }^{10}$ Further studies are, however, needed to confirm this.

The presbyopic correction for male patients at presentation was found to be higher than that for females in this study $(\mathrm{P}>0.05)$. This is consistent with the findings of Ezepue $^{20}$ in eastern Nigeria. However this is at variance with the findings of Pointer ${ }^{9}$ who recorded a higher magnitude of presbyopic correction for females. Several studies have shown that females present earlier with symptoms of presbyopia than males. ${ }^{8,9}$ Younger emmetropes require presbyopic correction of smaller magnitude than older emmetropes because of their higher amplitude of accommodation.

This study found presbyopia to be responsible for $12.8 \%$ of clinic attendance and majority of them $(73.2 \%)$ are civil servants. Provision of affordable near correction to civil servants will greatly improve the working man-hours of this population.

This study is limited in being a hospital-based case series and findings may not be representative of the true population situation.

\section{CONCLUSION}

The onset of presbyopia is earlier among patients presenting in the study location compared to Caucasians. Also, it occurs earlier in females compared to their male counterparts. The presbyopic correction for participants of this study was also higher than that of their Caucasian counterparts before the age of 55. The presbyopic requirement for males is higher than for females. However, when matched for age, there seems to be no clear relationship between presbyopic correction and gender in this study. Larger population-based studies are therefore required to further evaluate this relationship.

\section{REFERENCES}

1. IleshP, Sheila KW, EL-Maghraby. Presbyopia: Prevalence, impact and interventions. Community Eye Health 2007; 63: 40-41.

2. Abraham S. Duke-Elders Practice of Refraction. 9ed. Edinburgh: Longman Group Limited, 1978; 65-66.

3. Adefule AO, Valli NA. Presbyopia in Nigerians. East Afri Med J 1983; 60: 766-772.

4. Kaimbo K, Maertens K, Missotten L. Study of presbyopia in Zaire. Bull Soc Belge Ophthalmol 1987; 225: 149-156.

5. Miranda MN. The geographic factors in the onset of presbyopia. Trans Am Ophthalmol Soc 1979; 77: 603-621.

6. Jain IS, Ram J, Gupta A. Early onset of presbyopia. Am J Optima Physiol Opt 1982; 59: 1002-1004.

7. Kragha IK. Bifocal adds in Nigeria. Am J Optom Physiol Opt 1985; 62: 781-785.

8. Pointer JS. Presbyopic add II, Age related trend and a gender difference. Ophthalmic Physiol Opt 1995; 15: 241248.

9. Pointer JS. Gender related optical aspect of the onset of presbyopia. Ophthalmic Physiol Opt 2002; 22: 126-129.

10. Pointer JS. Presbyopic add I. Magnitude and distribution in a historic context. Ophthalmic Physiol Opt 1995; 15: 235240.

11. Kragha I, Hofstetter HW. Bifocal add and environmental temperature. Am J Optom Physiol Opt 1986; 63: 372-376.

12. Sherwin JC, Kufe JE, Kuper H, Islam FM, Muller A, Mathenge W. Functional presbyopia in a rural Kenyan population; the unmet presbyopic need. Clin Experiment Ophthalmol 2003; 36: 245-251.

13. Burke AG, Patel I, Munoz B, Kayongoya A, McHiwa W, and Schwarzwalder AW, et al. Prevalence of presbyopia in rural Tanzania: a population based study. Ophthalmology 2006; 113: 723-724.

14. Nwosu SNN. Ocular problem of young adults in rural Nigeria. International Ophthalmology 1998; 22: 259-263.

15. Amadi AN, Nwankwo BO, Ibe AI, Chukwuocha UM, Nwoga KS, Ogujiefor NC, et al. Common ocular problem in Aba metropolis of Abia State, eastern Nigeria. Pakistan J Social Sciences 2009; 6: 32-35.

16. Mc Donnel PJ, Lee P, Spritzear K, Lindblad AS, Hays RD. Association of presbyopia with vision targeted health related quality of life. Arch Ophthalmol 2003; 121: 15771581.

17. Patel I, Munoz B, Burke A, McHiwa W, Schwarzwalder AW et al. Impact of Presbyopia on quality of life in a rural African setting. Ophthalmology 2006; 113: 728-734.

18. Borish IM. Clinical Refraction $3^{\text {rd }}$ ed. Ilinois. Professional Press Inc.1975; 168-182.

19. Rambo VC. Further notes on the varying ages at which different people develop presbyopia. Am J Ophthalmol 1953; 36: 709-710. 
I R Azonobi

20. Ezepue UF. The distribution of presbyopia in the eye clinic of Eastern Nigeria Medical Centre, Enugu. Orient Journal of Medicine 2003; 15: 32-35.

21. Elkington AR, Frank HJ, Greaney MJ. Clinical Optics. $3^{\text {rd }}$ ed. London: Blackwell Science Ltd, 1984; 141-142.
22. Kim SU, Choi O. Average presbyopic addition for various age groups in Koreans. J Korean Ophthalmol Soc 1998; 23: 621-625.

23. Coates WR. Amplitude of accommodation in South African. B J Phys Opt 1955; 12: 76. 